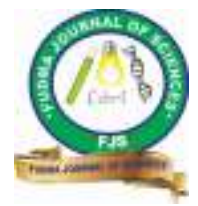

FUDMA Journal of Sciences (FJS)

ISSN online: $2616-1370$

ISSN print: 2645 - 2944

Vol. 4 No. 3, September, 2020, pp $207-214$

DOI: https://doi.org/10.33003/fjs-2020-0403-171

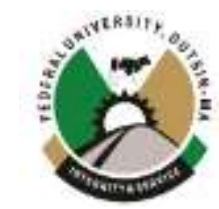

\title{
EFFICIENT FIFTH-ORDER CLASS FOR THE NUMERICAL SOLUTION OF FIRST ORDER ORDINARY DIFFERENTIAL EQUATIONS
}

\author{
*10lanegan, O. O. ${ }^{2}$ Aladesote O. I. \\ ${ }^{* 1}$ Department of Statistics, Federal Polytechnic, Ile-Oluji, Ondo State, Nigeria \\ ${ }^{2}$ Department of Computer Science, Federal Polytechnic, Ile-Oluji, Ondo State, Nigeria \\ *Corresponding Author: olaolanegan@fedpolel.edu.ng
}

\begin{abstract}
This paper proposes continuous linear multistep methods for the numerical solution of first-order ordinary differential equations (ODEs) with step number $k=1$ and $k=2$. These methods are used to integrate some first-order initial value problems and the block method developed from the continuous method using interpolation and collocation approach adopting power series approximation as the basis function for the derivation of these methods. These methods are found to be consistent, zero stable, convergent, and accurate. It is noteworthy that the results generated from these methods are significantly accurate and efficient when compared with existing methods, which will be effective in solving first-order Ordinary Differential Equations.
\end{abstract}

Keywords: Linear multistep methods (LMMs), ordinary differential equations (ODEs), block method, collocation and interpolation, and efficiency.

\section{INTRODUCTION}

We considered a First Order Ordinary Differential Equations with initial values as:

$$
y^{\prime}=f(x, y), y\left(x_{0}\right)=y_{0}
$$

$f$ is a continuously differentiable function within an interval satisfying the existence and uniqueness of solution (1). Ordinary Differential Equations are important tools in solving real-life problems. Various natural phenomena are modelled using ODEs to solve many problems. Thus, researchers have shown more interest in Ordinary Differential Equations in recent years. Collocation is the evaluation of the differential system of the basis function at some selected grid point while interpolation is the evaluation of the approximate solution also at some selected grid point. Collocation methods are widely considered as numerical methods for obtaining solutions to the ordinary differential equation of the form (1), solving integral; and differential equations in which the approximate solution is determined from the condition that the equation must be stratified at any given point. They involve the determination of an approximate solution in a set of functions called the basis function.

The usual way of solving (1) is to use a one-step explicit method such as Runge-Kutta of the same order of accuracy until enough values have been generated for multistep method to take off. The limitation of the linear multistep method is that it requires help to get started, as encountered in single-step method Aboiyar et al., 2015). The help required in getting started is called a predictor, while the starting values are called predictors (which are explicit) for (1), and the equation (1) is called the corrector (it is implicit). Hence, the procedure is called the predictor-corrector method.

James et al. (2013), proposed an order seven methods implemented in predictor-corrector mode. The method used the corrector to declare a continuous linear multistep method evaluated at some selected grid points to give a discrete linear multistep method of order seven for first ODEs. Dhaigude and Devkate (2017), developed a new sixth order method predictorcorrector method using Newton's forward interpolation formula to obtain the solution of first order initial value problem.

Bolarinwa et al., (2013), proposed a Taylor series approximation method to strengthen the weakness usually faced with Predictor-Corrector and Block methods. Jator and Li (2009), developed a block approach method to address the limitation of the predictor-corrector method.

Olanegan et al., (2015), developed a family of single-step continuous hybrid linear multistep methods (CHLMM) Taylor's series approximation as simultaneous numerical integrators over non-overlapping intervals values and for the implementation of the methods for first-order ordinary differential equations. This method takes care of the tedious process of writing subroutine and developing corrector as observed in the predictor-corrector. The approach provides the starting values, which makes it to be self-starting.

Areo and Adeniyi (2013), proposed a hybrid block method of order six to yield five consistent finite difference schemes, as simultaneous numerical integrators to form block method used to solve problems. This method provides better global error estimate and simpler form for further analytical work when compared with discrete ones.

Our interest in this research is to develop some continuous multistep hybrid and non-hybrid methods with $k=1$ and $k=2$ collocated at all the grids and off-grids points. The continuous methods are applied in a block-by-block approach to form our methods. These block methods are applied to solve 
first-order ordinary differential equations.

\section{DERIVATION OF METHODS}

Consider the power series of the form:

$$
y(x)=\sum_{j=0}^{k} a_{j} x^{j}
$$

the first derivative of (2) gives:

$$
y^{\prime}(x)=\sum_{j=0}^{k} j a_{j} x^{j-1}
$$

Putting (3) into (1) we obtain the differential system

$$
\sum_{j=0}^{k} j a_{j} x^{j-1}=f(x, y)
$$

\section{Development of Method 1}

Interpolating (2) at $x=x_{n+u}, u=0$, and collocating (3) at $x=x_{n+\varphi}, \varphi=0,1,2$ gives a system of nonlinear equation of the form: $A X=U$

where, $A=\left[a_{0}, a_{1}, a_{2}, a_{3}\right]^{T} \quad U=\left[f_{n}, f_{n+1}, f_{n+2}, y_{n}\right]^{T} \quad X=\left[\begin{array}{cccc}1 & x_{n} & x_{n}^{2} & x_{n}^{3} \\ 0 & 1 & 2 x_{n} & 3 x_{n}^{2} \\ 0 & 1 & 2 x_{n+1} & 3 x_{n+1}^{2} \\ 0 & 1 & 2 x_{n+2} & 3 x_{n+2}^{2}\end{array}\right]$

using Gaussian's elimination method for (5), we have a continuous method of the form:

$$
y(t)=\alpha_{\theta}(t) y_{n+\theta}+h\left[\sum_{\eta=0}^{k} \beta_{k}(t) f_{n+k}\right]
$$

where, $\theta=0, \theta=0, \eta=0,1,2, \eta=0,1,2, k=2, \kappa=2, f_{n+k}=f\left(x_{n}+k h\right)$

Thus, using this transformation

$t=\frac{x-x_{n+k}}{h}$

We have a continuous method of the form:

$\alpha_{0}(t)=1$

$\beta_{0}(t)=\frac{h}{24}\left[10+24 t-18 t^{2}+t^{3}\right]$

$\beta_{1}(t)=\frac{h}{3}\left[2+3 t^{2}-t^{3}\right]$

$\beta_{2}(t)=\frac{h}{24}\left[-2-6 t^{2}+4 t^{3}\right]$

Evaluating (7), at the end point and the non-interpolation point which mean $x=x_{n+2}$ and $x=x_{n+1}$ give a block method of the form:

$$
\begin{aligned}
& y_{n+2}-y_{n}=\frac{h}{3}\left(f_{n+2}+4 f_{n+1}+f_{n}\right) \\
& y_{n+1}-y_{n}=\frac{h}{12}\left(-f_{n+2}+8 f_{n+1}+5 f_{n}\right)
\end{aligned}
$$




\section{Development of Method 2}

Interpolating (2) at $x=x_{n+u}, u=0$, and collocating (3) at $x=x_{n+\varphi}, \varphi=0, \frac{1}{2}, 1$ gives a system of nonlinear equation of the form:

$A X=U$

where, $\quad A=\left[a_{0}, a_{1}, a_{2}, a_{3}\right]^{T} \quad U=\left[f_{n}, f_{n+1}, f_{n+\frac{1}{2}}, y_{n}\right]^{T} \quad X=\left[\begin{array}{cccc}1 & x_{n} & x_{n}^{2} & x_{n}^{3} \\ 0 & 1 & 2 x_{n} & 3 x_{n}^{2} \\ 0 & 1 & 2 x_{n+\frac{1}{2}} & 3 x_{n+\frac{1}{2}}^{2} \\ 0 & 1 & 2 x_{n+1} & 3 x_{n+1}^{2}\end{array}\right]$

using Gaussian's elimination method for (11), we have a continuous method of the form:

$y(t)=\alpha_{\theta}(t) y_{n+\theta}+h\left[\sum_{\eta=0}^{k} \beta_{k}(t) f_{n+k}\right]$

where, $\theta=0, \eta=0, \frac{1}{2}, 1, k=1, f_{n+k}=f\left(x_{n}+k h\right)$

Thus, using the transformation

$t=\frac{x-x_{n+k}}{h}$

to produce a continuous method of the form:

$\alpha_{0}(t)=1$

$\beta_{0}(t)=\frac{h}{6}\left[9 t-9 t^{2}+4 t^{3}\right]$

$\beta_{1 / 2}(t)=\frac{h}{3}\left[6 t^{2}-8 t^{3}\right]$

$\beta_{1}(t)=\frac{h}{6}\left[-3 t^{2}+4 t^{3}\right]$

at $t=2$ and $t=\frac{1}{2}$ in (11), which mean $x=x_{n+1}$ and $x=x_{n+\frac{1}{2}}$ we have the block method to be the form:

$y_{n+1}-y_{n}=\frac{h}{6}\left(f_{n+1}+4 f_{n+\frac{1}{2}}+f_{n}\right)$

$y_{n+\frac{1}{2}}-y_{n}=\frac{h}{24}\left(-f_{n+1}+8 f_{n+\frac{1}{2}}+5 f_{n}\right)$

\section{ANALYSIS OF THE METHODS}

Zero Stability

A block method of the form

$A^{(0)} Y_{m}=A^{(i)} Y_{m-1}+h^{\mu}\left[B^{i} F_{m}+B^{(0)} F_{m-1}\right]$

is said to be zero stable, if the roots of the first characteristic polynomial

$\operatorname{det}\left[\lambda A^{(0)}-A^{(i)}\right]=0$

Satisfying $|\lambda| \leq 1$ for the roots with $|\lambda| \leq 1$ not exceed the order of the differential equations [8]. For our methods, we have 


$$
\begin{aligned}
& \left.A=\left[\begin{array}{lllll}
1 & 0 & 0 & 0 & 0 \\
0 & 1 & 0 & 0 & 0 \\
0 & 0 & 1 & 0 & 0 \\
0 & 0 & 0 & 1 & 0 \\
0 & 0 & 0 & 0 & 1
\end{array}\right)-\left(\begin{array}{ccccc}
0 & 0 & 0 & 0 & 1 \\
0 & 0 & 0 & 0 & 1 \\
0 & 0 & 0 & 0 & 1 \\
0 & 0 & 0 & 0 & 1 \\
0 & 0 & 0 & 0 & 1
\end{array}\right)\right]=0 \\
& A=z^{4}(z-1)=0, z=[0,0,0,0]^{T}
\end{aligned}
$$

Thus, we conclude that the methods are zero stable.

\section{ORDER OF ACCURACY AND ERROR CONSTANT}

A Block Linear Multistep Method is said to be of order $\mathrm{p}$, if $\mathrm{p}$ is the largest positive integer for which $C_{0}=C_{1}=C_{2}=\cdots,=C_{p}=0$ and $C_{p+1} \neq 0$ is called the error constant and $C_{p+1} h^{p+1} y^{p+1}\left(x_{n}\right)$ is the principal Local

Truncation Error (LTE) at the point $x_{n}$. Expanding our methods by Taylor series expansion, comparing coefficients equating to zero [6]. Hence, the two block methods is said to be of uniform order $p=[5,5,5,5]^{T}$ with error constants of $C_{p+1}=\left[-\frac{1}{90}, \frac{13}{360}\right]^{T}$ and $C_{p+1}=\left[-\frac{1}{2880}, \frac{1}{2304}\right]^{T}$.

\section{Consistency}

According to Olanegan et al., the methods are consistent if:

i. the order of the method is $p \geq 1$ hence our $p=5 \geq 1$

ii. $\quad \alpha_{2}=1, \alpha_{0}=1$. Thus, $\sum_{j=0} \alpha_{j}=1-1=0$

iii. $\sum \alpha_{j}=0, \rho^{\prime}(r)=0$ when $r=1$

iv. $\rho^{\prime \prime}(r)=2 ! \sigma(r)$ when $r=1$

Since our Methods satisfied the above condition. We conclude that the methods are consistent.

\section{Convergence}

According to Olanegan et al., for a method to be convergence, it must be consistent and zero stable. Since these conditions are satisfied, then the methods are said to be convergent.

\section{NUMERICAL EXAMPLES}

\section{Problem 1}

$$
y^{\prime}+y=0, \quad y(0)=1, h=0.1
$$

Exact Solution: $y(x)=e^{-x}$

\section{Problem 2}

$y^{\prime}-x y=0, \quad y(0)=1, h=0.1$

Exact Solution: $y(x)=e^{x^{2}}$

\section{Problem 3}

$y^{\prime}=x+y \quad y(0)=1, h=0.1 \quad 0 \leq x \leq 1$

Exact Solution: $y(x)=-(1+x)+2 e^{x}$ 
NUMERICAL RESULTS

Table 1: Numerical Result for Method 1 to solve Problem 1 and Comparison

Table 1: Numerical Result for Method 1 to solve Problem 1 and Comparison
\begin{tabular}{|c|l|l|l|l|l|}
\hline$x$ & Exact Solution & Numerical Solution & Error & Time & Error in [1] \\
\hline 0.1 & 0.90483741803596 & 0.90483800989126 & $5.9185 \mathrm{E}-09$ & 0.0050 & $8.1964 \mathrm{E}-008$ \\
\hline 0.2 & 0.81873075307798 & 0.81873182414398 & $1.0710 \mathrm{E}-08$ & 0.0096 & $1.4832 \mathrm{E}-007$ \\
\hline 0.3 & 0.74081822068172 & 0.74081967439308 & $1.4537 \mathrm{E}-08$ & 0.0144 & $3.8269 \mathrm{E}-008$ \\
\hline 0.4 & 0.67032004603564 & 0.67032179986613 & $1.7538 \mathrm{E}-08$ & 0.0171 & $3.5630 \mathrm{E}-008$ \\
\hline 0.5 & 0.60653065971263 & 0.60653264337760 & $1.9836 \mathrm{E}-08$ & 0.0194 & $2.7287 \mathrm{E}-007$ \\
\hline 0.6 & 0.54881163609403 & 0.54881378996787 & $2.1538 \mathrm{E}-08$ & 0.0218 & $2.9613 \mathrm{E}-007$ \\
\hline 0.7 & 0.49658530379141 & 0.49658757751541 & $2.2737 \mathrm{E}-08$ & 0.0242 & $5.5945 \mathrm{E}-007$ \\
\hline 0.8 & 0.44932896411722 & 0.44933131537576 & $2.3512 \mathrm{E}-08$ & 0.0266 & $5.7732 \mathrm{E}-007$ \\
\hline 0.9 & 0.40656965974060 & 0.40657205318643 & $2.3934 \mathrm{E}-08$ & 0.0290 & $8.4926 \mathrm{E}-007$ \\
\hline 1.0 & 0.36787944117144 & 0.36788184748261 & $2.4063 \mathrm{E}-08$ & 0.0315 & $8.4391 \mathrm{E}-007$ \\
\hline
\end{tabular}

Table 2: Numerical Result for Method 2 to solve Problem 1 and Comparison

\begin{tabular}{|l|c|l|l|l|l|}
\hline$x$ & Exact Solution & Numerical Solution & Error & Time & Error in [1] \\
\hline 0.1 & 0.90483741803596 & 0.90483756565329 & $1.4761 \mathrm{E}-10$ & 0.0045 & $8.1964 \mathrm{E}-008$ \\
\hline 0.2 & 0.81873075307798 & 0.81873102021737 & $2.6713 \mathrm{E}-10$ & 0.0092 & $1.4832 \mathrm{E}-007$ \\
\hline 0.3 & 0.74081822068172 & 0.74081858325831 & $3.6257 \mathrm{E}-09$ & 0.0140 & $3.8269 \mathrm{E}-008$ \\
\hline 0.4 & 0.67032004603564 & 0.67032048346617 & $3.6257 \mathrm{E}-09$ & 0.0177 & $3.5630 \mathrm{E}-008$ \\
\hline 0.5 & 0.60653065971263 & 0.60653115446706 & $3.6257 \mathrm{E}-09$ & 0.0213 & $2.7287 \mathrm{E}-007$ \\
\hline 0.6 & 0.54881163609403 & 0.54881217330085 & $3.6257 \mathrm{E}-09$ & 0.0248 & $2.9613 \mathrm{E}-007$ \\
\hline 0.7 & 0.49658530379141 & 0.49658587089043 & $3.6257 \mathrm{E}-09$ & 0.0290 & $5.5945 \mathrm{E}-007$ \\
\hline 0.8 & 0.44932896411722 & 0.44932955055432 & $3.6257 \mathrm{E}-09$ & 0.0322 & $5.7732 \mathrm{E}-007$ \\
\hline 0.9 & 0.40656965974060 & 0.40657025669965 & $3.6257 \mathrm{E}-09$ & 0.0367 & $8.4926 \mathrm{E}-007$ \\
\hline 1.0 & 0.36787944117144 & 0.36788004133915 & $5.9695 \mathrm{E}-08$ & 0.0402 & $8.4391 \mathrm{E}-007$ \\
\hline
\end{tabular}

Table 3: Numerical Result for Method 1 to solve Problem 2 and Comparison

\begin{tabular}{|l|c|l|l|l|l|}
\hline$x$ & Exact Solution & Numerical Solution & Error & Time & Error in [3] \\
\hline 0.1 & 1.01005016708417 & 1.01005003025771 & $1.368 \mathrm{E}-09$ & 0.0055 & 0.000000000 \\
\hline 0.2 & 1.04081077419239 & 1.04081020290595 & $5.712 \mathrm{E}-09$ & 0.0072 & 0.000000000 \\
\hline 0.3 & 1.09417428370521 & 1.09417287622282 & $1.407 \mathrm{E}-09$ & 0.0113 & 0.000000000 \\
\hline 0.4 & 1.17351087099181 & 1.17350802531083 & $2.845 \mathrm{E}-08$ & 0.0129 & $2.00 \mathrm{E}-08$ \\
\hline 0.5 & 1.28402541668774 & 1.28402018730910 & $5.229 \mathrm{E}-08$ & 0.0147 & $6.80 \mathrm{E}-08$ \\
\hline 0.6 & 1.43332941456034 & 1.43332028673732 & $9.127 \mathrm{E}-08$ & 0.0163 & $1.09 \mathrm{E}-07$ \\
\hline 0.7 & 1.63231621995538 & 1.63230074357230 & $1.547 \mathrm{E}-07$ & 0.0183 & $1.63 \mathrm{E}-07$ \\
\hline 0.8 & 1.89648087930495 & 1.89645506523525 & $2.581 \mathrm{E}-07$ & 0.0201 & $2.37 \mathrm{E}-07$ \\
\hline 0.9 & 2.24790798667646 & 2.24786529966716 & $4.268 \mathrm{E}-07$ & 0.0218 & $3.40 \mathrm{E}-07$ \\
\hline 1.0 & 2.71828182845903 & 2.71821148946015 & $7.033 \mathrm{E}-07$ & 0.0235 & $5.58 \mathrm{E}-07$ \\
\hline
\end{tabular}

Table 4: Numerical Result for Method 2 to solve Problem 2 and Comparison

\begin{tabular}{|l|l|l|l|l|l|}
\hline$x$ & Exact Solution & Numerical Solution & Error & Time & Error in [3] \\
\hline 0.1 & 1.01005016708417 & 1.01005013337654 & $3.370 \mathrm{E}-10$ & 0.0009 & 0.00000 \\
\hline 0.2 & 1.04081077419239 & 1.04081063230877 & $1.418 \mathrm{E}-09$ & 0.0064 & 0.00000 \\
\hline 0.3 & 1.09417428370521 & 1.09417393306249 & $3.506 \mathrm{E}-09$ & 0.0019 & 0.00000 \\
\hline 0.4 & 1.17351087099181 & 1.17351016077859 & $7.102 \mathrm{E}-09$ & 0.0117 & $2.00 \mathrm{E}-08$ \\
\hline 0.5 & 1.28402541668774 & 1.28402410991864 & $1.306 \mathrm{E}-08$ & 0.0135 & $6.80 \mathrm{E}-08$ \\
\hline 0.6 & 1.43332941456034 & 1.43332713138770 & $2.283 \mathrm{E}-08$ & 0.0099 & $1.09 \mathrm{E}-07$ \\
\hline 0.7 & 1.63231621995538 & 1.63231234569132 & $3.874 \mathrm{E}-08$ & 0.0168 & $1.63 \mathrm{E}-07$ \\
\hline 0.8 & 1.89648087930496 & 1.89647441271315 & $6.466 \mathrm{E}-08$ & 0.0147 & $2.37 \mathrm{E}-07$ \\
\hline 0.9 & 2.24790798667649 & 2.24789728676892 & $1.069 \mathrm{E}-07$ & 0.0188 & $3.40 \mathrm{E}-07$ \\
\hline 1.0 & 2.71828182845908 & 2.71826418752465 & $1.764 \mathrm{E}-07$ & 0.0944 & $5.58 \mathrm{E}-07$ \\
\hline
\end{tabular}


Table 5: Numerical Result for Method 1 to solve Problem 3 and Comparison

\begin{tabular}{|l|l|l|l|l|}
\hline$x$ & Exact Solution & Numerical Solution & Error & Error in [3] \\
\hline 0.1 & 1.03388166734330 & 1.03388166738420 & $4.090 \mathrm{E}-11$ & $1.69 \mathrm{E}-07$ \\
\hline 0.2 & 1.06675678777170 & 1.06675678785246 & $8.076 \mathrm{E}-11$ & $3.74 \mathrm{E}-07$ \\
\hline 0.3 & 1.09859628024550 & 1.09859628036501 & $1.195 \mathrm{E}-10$ & $6.210 \mathrm{E}-07$ \\
\hline 0.4 & 1.12937207493916 & 1.12937207509627 & $1.571 \mathrm{E}-10$ & $9.140 \mathrm{E} 07$ \\
\hline 0.5 & 1.15905714062147 & 1.15905714081491 & $1.934 \mathrm{E}-10$ & $2.300 \mathrm{E}-07$ \\
\hline 0.6 & 1.18762551102154 & 1.18762551125002 & $2.284 \mathrm{E}-10$ & $3.92 \mathrm{E}-07$ \\
\hline 0.7 & 1.21505231015499 & 1.21505231041716 & $2.621 \mathrm{E}-10$ & $6.310 \mathrm{E}-07$ \\
\hline 0.8 & 1.2413137765854 & 1.24131377687988 & $2.944 \mathrm{E}-10$ & $9.170 \mathrm{E}-07$ \\
\hline 0.9 & 1.26638728659754 & 1.26638728692280 & $3.252 \mathrm{E}-10$ & $1.213 \mathrm{E}-07$ \\
\hline 1.0 & 1.29025137625933 & 1.29025137661388 & $3.545 \mathrm{E}-10$ & $5.890 \mathrm{E}-07$ \\
\hline
\end{tabular}

Table 6: Numerical Result for Method 2 to solve Problem 3 and Comparison

\begin{tabular}{|l|l|l|l|l|}
\hline$x$ & Exact Solution & Numerical Solution & Error & Error in [3] \\
\hline 0.1 & 1.01604386798991 & 1.01604478773994 & $4.41 \mathrm{E}-12$ & $1.69 \mathrm{E}-07$ \\
\hline 0.2 & 1.02616151045788 & 1.02614140035864 & $8.75 \mathrm{E}-12$ & $3.74 \mathrm{E}-07$ \\
\hline 0.3 & 1.05816454641475 & 1.05916354401623 & $1.303 \mathrm{E}-11$ & $6.210 \mathrm{E}-07$ \\
\hline 0.4 & 1.07671640027179 & 1.07561640125166 & $1.722 \mathrm{E}-11$ & $9.140 \mathrm{E} 07$ \\
\hline 0.5 & 1.09493758192488 & 1.09473758190361 & $2.133 \mathrm{E}-11$ & $2.300 \mathrm{E}-07$ \\
\hline 0.6 & 1.11252084314177 & 1.11252074311742 & $2.536 \mathrm{E}-11$ & $3.92 \mathrm{E}-07$ \\
\hline 0.7 & 1.12975911074687 & 1.10973911062756 & $2.931 \mathrm{E}-11$ & $6.310 \mathrm{E}-07$ \\
\hline 0.8 & 1.14654548988987 & 1.14554547995660 & $3.317 \mathrm{E}-11$ & $9.170 \mathrm{E}-07$ \\
\hline 0.9 & 1.16687326621384 & 1.16257326617700 & $3.694 \mathrm{E}-11$ & $1.213 \mathrm{E}-07$ \\
\hline 1.0 & 1.18871590863630 & 1.15871590859568 & $4.062 \mathrm{E}-11$ & $5.890 \mathrm{E}-07$ \\
\hline
\end{tabular}

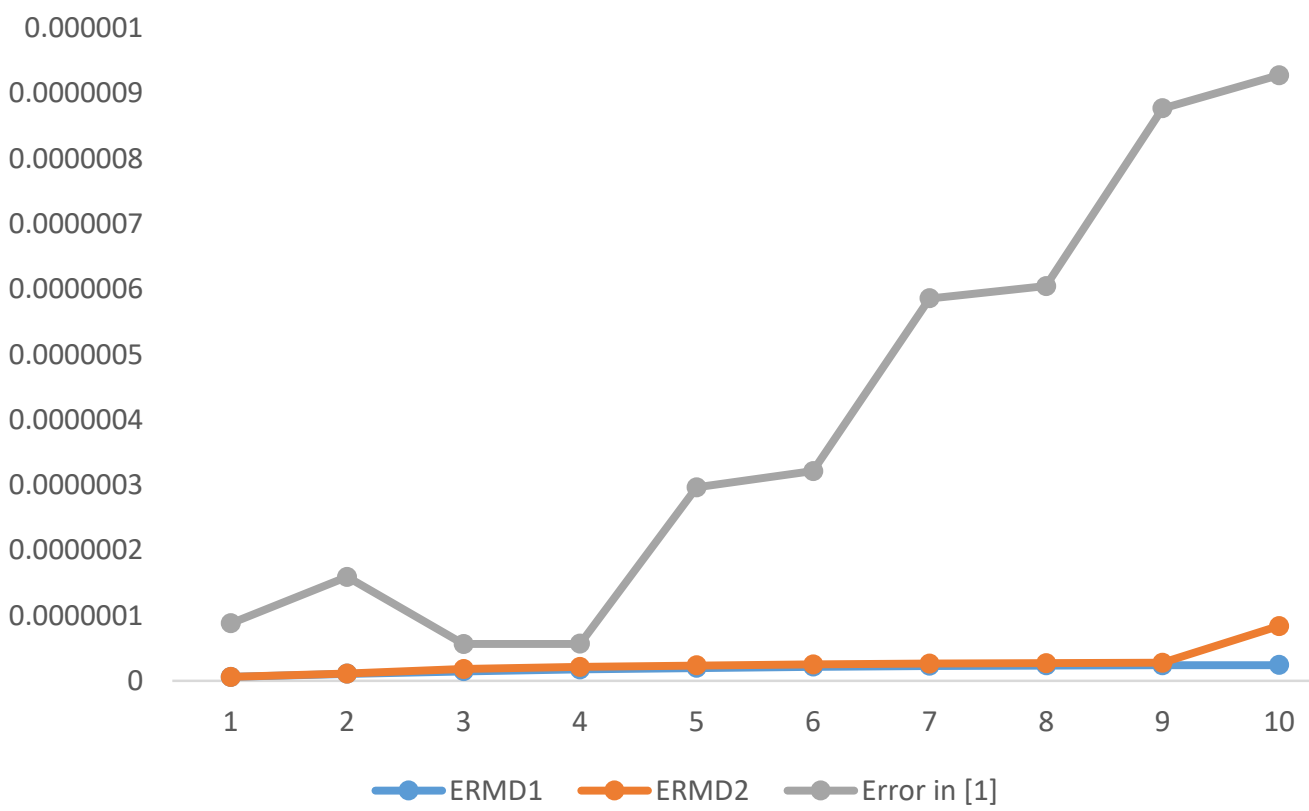

Figure 1: Comparison of Errors with Problem 1 


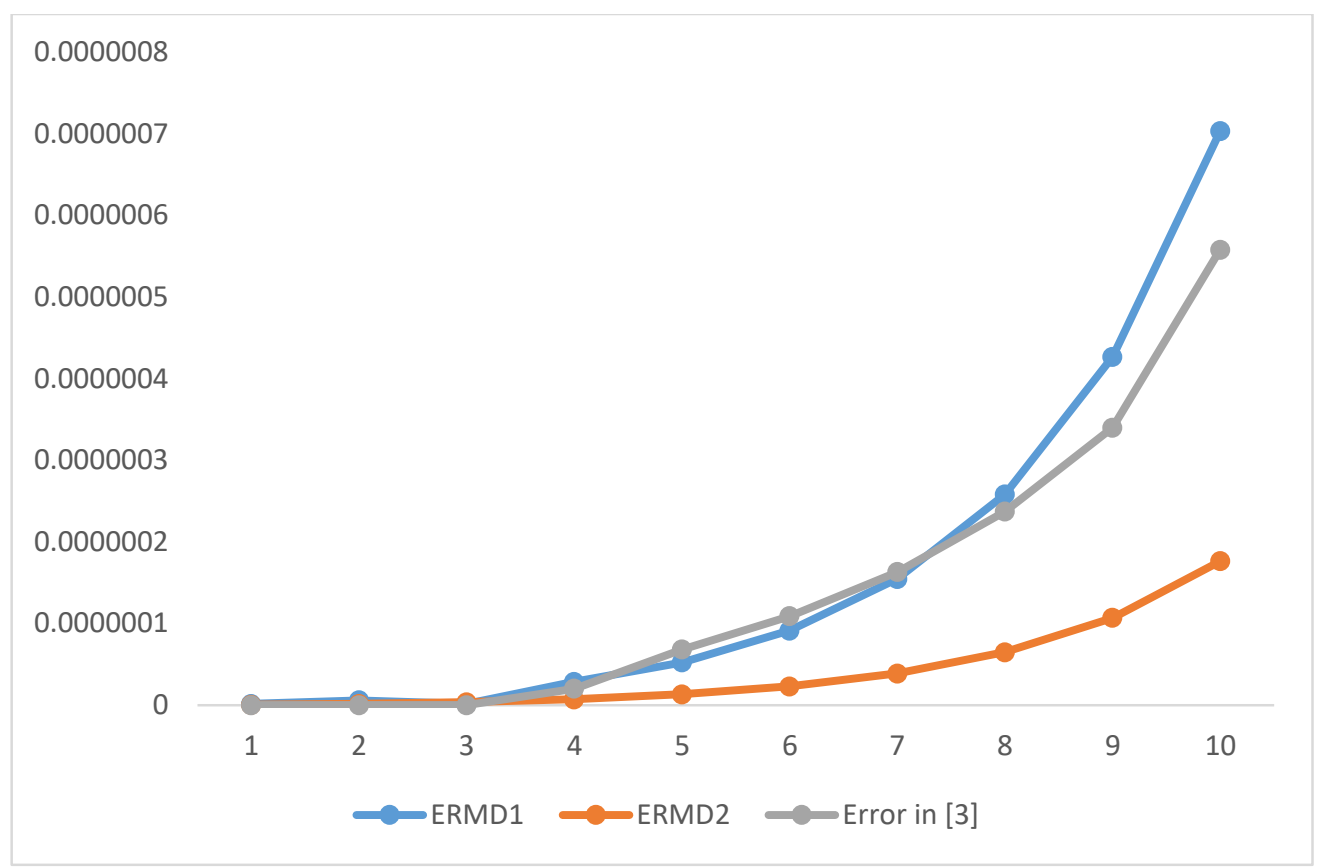

Figure 2: Comparison of Errors with Problem 2

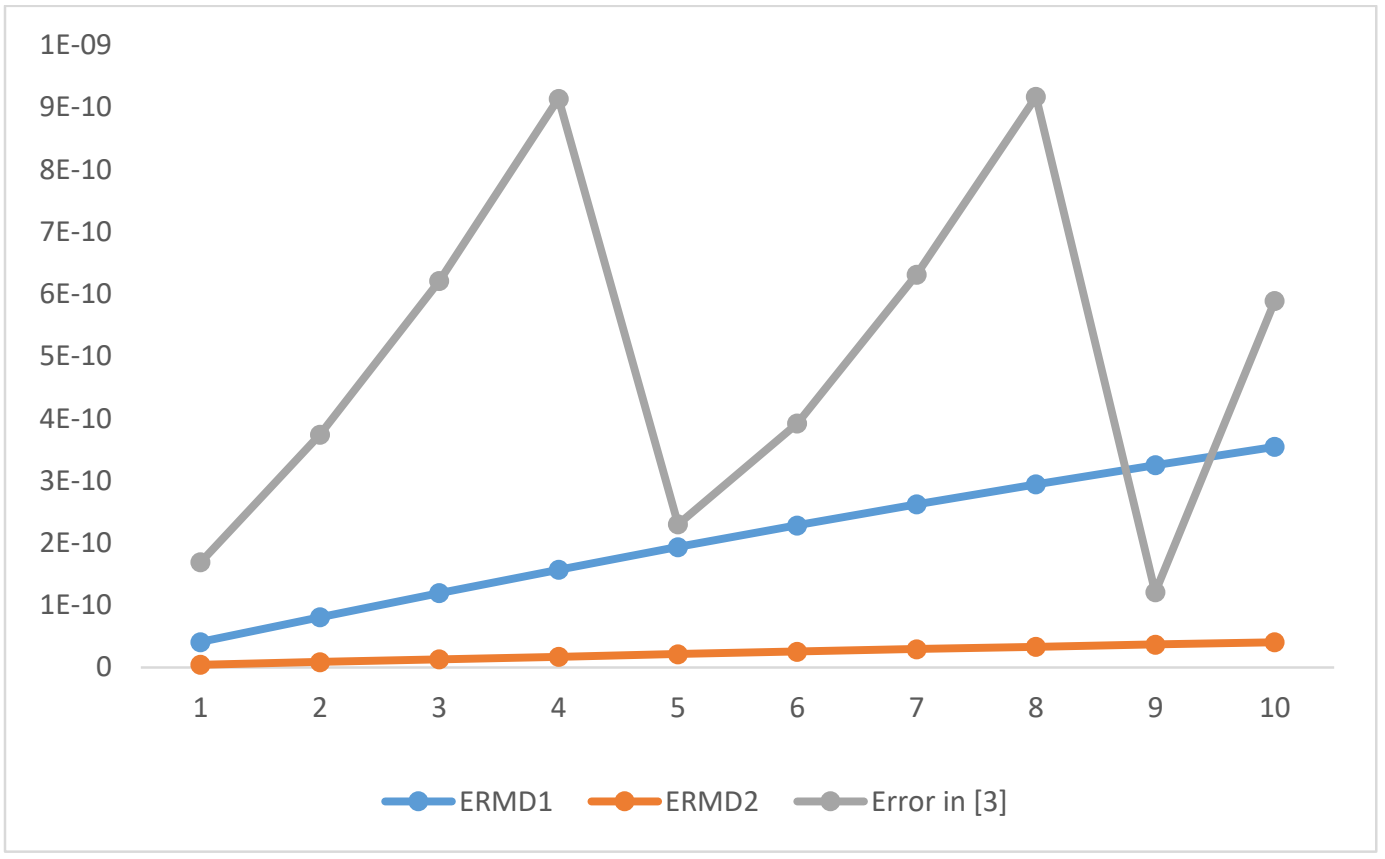

Figure 3: Comparison of Errors with Problem 3

Note:

ERMD1: Error from the Numerical Result of Method 1

ERMD2: Error from Numerical Result of Method 2

\section{DISCUSSION OF RESULTS}

Table $(1-6)$ and Figure $(1-3)$ display the results generated from methods 1 and 2 , using it to solve problems $(1-3)$. From the results and the figures as presented, it shows that method 2 with a single step and one off-step point performs better than method 1 in terms of accuracy and computational time. Also, the results from our methods show better performance when compared with [1] and [3], when used it to solve the same problem as presented in Tables $(1-6)$.

\section{CONCLUSION}

This research has presented a class of continuous methods for the numerical integration of first-order initial value problems. It is noteworthy that the results generated from the methods are significantly accurate and efficient in terms of performance when compared with existing works. This methods is effective 
in solving first-order differential equations.

\section{REFERENCES}

Aboiyar T., Luga T., and Iyorter B.V. (2015) "Derivation of Continuous Linear Multistep Methods Using Hermite Polynomials as Basis Functions", American Journal of Applied Mathematics and Statistics, 3(6), 220 - 225.

James A. A., Adesanya A. O., and Fasasi M. K. (2013) "Starting Order Seven Method Accurately for the solution of First Initial Value Problems of First Order Ordinary Differential Equations", Progress in Applied Mathematics 6(1), 30-39.

R. M. Dhaigude and R. K. Devkate (2017) "Solution of First Order Initial Value Problem by Sixth Order Predictor Corrector Method". Global Journal of Pure and Applied Mathematics. ISSN 0973-1768 13 (6), 2277 - 2290.

http://www.ripublication.com/gjpam.htm

Bolarinwa B., Akinduko O. B., Duromola M. K., (2013) “A Fourth Order One-Step Hybrid Method for the Numerical Solution of Initial Value Problems of Second Order Ordinary Differential Equations", Journal of Natural Sciences 1(2):7985 .
Jator, S.N. and Li, J. (2009) "A Self-Starting Linear Multistep Method for a Direct Solution of the General Second-Order Initial Value Problem", International Journal of Computer Mathematics, 86(5), 827-836.

Olanegan, O. O., Ogunware, B. G., Omole E. O., Oyinloye, T. S. and Enoch B. T. (2015) "Some Variable Hybrids Linear Multistep Methods for Solving First Order Ordinary Differential" IOSR Journal of Mathematics (IOSR-JM) 11(5), 8-13.

Areo E. A. and Adeniyi R. B. (2013) "Sixth-order Hybrid Block Method for the Numerical Solution of First Order Initial Value Problems", Journal of Mathematical Theory and Modelling, 3(8), 113-120. 